\title{
História e Filosofia da Ciência no ensino de Biologia Celular
}

\author{
History and Philosophy of Science in the teaching of Cell Biology
}

\author{
Francisco Breno Silva Teófilo ${ }^{1}$ \\ https:// orcid.org/0000-0002-9538-796X \\ Maria Izabel Gallão ${ }^{2}$ \\ https://orcid.org/0000-0001-9299-0803
}

\begin{abstract}
Resumo: A utilização de abordagens históricas e filosóficas tornou-se cada vez mais valorizada na busca de melhorar o ensino e a aprendizagem das Ciências. No entanto, é preciso atentar para o seu uso, já que entendimentos distorcidos da natureza da ciência podem ser expressos aos estudantes como verdades. O objetivo deste artigo é investigar como elementos relacionados com a História e a Filosofia da Ciência são inseridos em capítulos que introduzem o estudo da célula em 20 livros didáticos de Biologia para o ensino médio usados no período de 1965 a 2015. Foram estabelecidas categorias de avaliação: conteúdo teórico, ilustrações, exercícios, atividades e projetos, e, de recursos adicionais. Mediante análise de conteúdo foi detectada a presença de inserções que podem apresentar uma perspectiva superficial, linear, acumulativa, infalível, individualista e anacrônica da ciência. $\mathrm{Na}$ análise dos resultados foram evidenciadas tendências, carências e, principalmente, traçadas possibilidades quanto ao uso desses elementos no Ensino de Biologia Celular.
\end{abstract}

Palavras-chave: Ensino de biologia. Ensino médio. Livro didático. História da Ciência. Filosofia da Ciência.

\begin{abstract}
The use of historical and philosophical approaches has become a valued tool in the pursuit of improvements in Science teaching and learning processes. However, attention must be paid to how they are used since distorted understandings of the nature of science can be expressed to students as truths. The aim of this paper is to investigate the elements related to the History and Philosophy of Science that have been inserted in chapters that introduce the study of the cell in 20 High School Biology textbooks between 1965 and 2015. The evaluation categories have been established: theoretical content, illustrations, exercises, activities and projects, and, the existence of additional resources. Content analysis indicates that, throughout the years, the presence of insertions could lead to a superficial, linear, cumulative, infallible, individualistic and anachronistic view of science. The results showed trends, needs, and especially possibilities regarding the use of these elements in Cell Biology Teaching.
\end{abstract}

Keywords: Biology teaching. Secondary school. Textbook. History of science. Philosophy of science.

\footnotetext{
${ }^{1}$ Universidade Estadual de Campinas (Unicamp), Instituto de Biologia, Programa de Pós-Graduação em Biologia Celular e Estrutural, Campinas, SP, Brasil. E-mail: f211599@dac.unicamp.br.

${ }^{2}$ Universidade Federal do Ceará (UFC), Centro de Ciências, Departamento de Biologia, Fortaleza, CE, Brasil.
} 


\section{Introdução}

Não é de hoje que temas de relevância científica auferem espaço no cotidiano da população em geral por meio dos mais distintos meios de divulgação. Ao analisar as relações existentes entre educação científica e sociedade, Vale (2009) ressalta o fato de que o reconhecimento da Ciência quanto a sua importância social para a resolução de problemas e desenvolvimento geral de uma sociedade é praticamente indiscutível. Apesar desse quase consenso, ainda é possível perceber, principalmente quando se analisa o contexto escolar, a existência de várias dificuldades no ensino-aprendizagem das Ciências que, por vezes, são classificadas como abstratas e setorizadas. Tais empecilhos são amplificados mediante associação com os resultados da "crise no ensino contemporâneo de ciências, com estudantes e professores desmotivados e também os elevados índices de analfabetismo científico" (SILVA, 2006, p. 9, grifo nosso).

Imersos nessa realidade e cientes do desafio a ser enfrentado, pesquisadores e professores acham-se numa "busca por opções alternativas, tanto epistêmicas, quanto metodológicas de trabalho" (BATISTA; LUCCAS, 2004, p. 102). Dentre as possibilidades consideradas, Silva (2006) destaca a utilização de elementos de História e Filosofia da Ciência no ensino como um dos potenciais recursos para atenuar ou, até mesmo, superar essa crise. No Brasil, as abordagens históricas e filosóficas foram ganhando, ainda que de maneira singela, espaço em propostas e diretrizes oficiais, além de tornar-se objeto de estudo para muitos grupos e pesquisadores em diversas instituições do país. Dentre um dos principais exemplos de documentos voltados para a educação básica, estão os Parâmetros Curriculares Nacionais (PCN) para o Ensino Médio que recomendam, em meio as suas competências e habilidades voltadas para a área de Ciências da Natureza, Matemática e suas tecnologias, o reconhecimento das "ciências como construções humanas" (BRASIL, 2000, p. 13) por via da história. Já no que se refere ao campo da formação docente, citam-se as Diretrizes Curriculares para os cursos de Ciências Biológicas (2001) que salientam a importância de se assimilar "conhecimentos básicos de: História, Filosofia e Metodologia da Ciência, Sociologia e Antropologia, para dar suporte à sua atuação profissional na sociedade" (BRASIL, 2001, p. 6).

Cicillini (1992, p. 7), ao justificar o emprego de uma abordagem histórica no Ensino de Biologia para o nível médio, propõe que toda "a aquisição do conhecimento cientificamente produzido pela sociedade deve acontecer de forma organizada e sistematizada pelo processo de aprendizagem, para que o aluno [...] atue sobre a sua realidade de forma crítica". Para tanto, a autora aponta a importância e necessidade de planejamentos adequados e exalta a figura do professor que, em decorrência das inserções e debates acerca da História da Ciência, passará a ser protagonista do processo, tentando evitar em sua prática pedagógica uma atitude caracterizada pela mera propagação de informações sem a devida realização de reflexões e questionamentos.

Reforçando o coro dos que defendem a inserção de perspectivas históricas e filosóficas como alternativa para melhorar o ensino dos conteúdos científicos, El-Hani (2006, p. 3, grifo do autor), expressa a ideia de que “[...] a aprendizagem das ciências deve ser acompanhada por uma aprendizagem sobre as ciências (ou sobre a natureza da ciência)".

Corroborando essa ideia, Moura (2014, p. 32) interpreta a expressão natureza da ciência "como um conjunto de elementos que tratam da construção, estabelecimento e organização do conhecimento científico". Ainda consoante o autor, a História e Filosofia da Ciência, 
baseada em suas características, demonstra ser a alternativa que pode possibilitar, por meio da contextualização, uma melhor compreensão desses conceitos, haja vista o fato de que seus "estudos historiográficos trazem elementos que subsidiam discussões acerca da gênese do conhecimento científico e os fatores internos e externos que a influenciam" (MOURA, 2014, p. 33).

Mesmo com tantas precauções a serem tomadas, o uso correto da História e Filosofia da Ciência pode facilitar o entendimento de conteúdos científicos que carecem de melhor contextualização. Uma das áreas que pode ser beneficiada é reconhecidamente a Biologia Celular, lembrada por exibir tanto as células quanto seus componentes celulares de modo demasiadamente descritivo. Além disso, Batisteti, Araújo e Caluzi (2009, p. 29) comentam que, geralmente, essas explicações vêm "em detrimento de informações sobre os procedimentos científicos”. Myriam Krasilchik (KRASILCHIK, 2011) já alertava para esse fato, ao comentar que, majoritariamente, os programas de Biologia para o Ensino Médio do começo dos anos de 1990 denotam intensiva orientação descritiva, ao tentarem explicar os conceitos biológicos. $\mathrm{Na}$ ocasião, a autora argumentou que "isso é evidenciado quando se nota que o assunto 'estrutura celular' predomina aparecendo em $96 \%$, e o assunto do 'metabolismo celular', em cerca de 70\% das propostas curriculares" (KRASILCHIK, 2011, p. 19).

Embora exista um consenso de que o emprego de abordagens históricas possa reverter situações como essa, deve-se atentar não somente para quantidade, mas também para qualidade das abordagens que chegam às salas de aula. Pagliarini (2007, p. 103, grifo nosso) explica que:

[...] ao lado das potencialidades que a história e a filosofia da ciência traz e que podem promover o ensino de ciências, caminham alguns elementos que podem prejudicar o seu ensino. Entre eles, a presença de uma história distorcida e demasiada simples, apresentada de forma a valorizar nos conhecimentos e teorias passadas apenas as ideias aceitas atualmente como corretas. Esse tipo de narrativa histórica seleciona e molda alguns episódios e personagens para uma apresentação linear e simples, e reforçam concepções de senso comum sobre a natureza da ciência.

Com efeito, este estudo foi realizado com o intuito de analisar como a História e Filosofia da Ciência são abordadas nos conteúdos teóricos de livros didáticos, voltados para o ensino médio, utilizados de 1965 a 2015. Para isso, foi realizada uma análise quali-quantitativa em 20 obras onde o tema Citologia/Biologia Celular era abordado. Salienta-se, todavia, que o objetivo deste trabalho não é julgar qual livro didático se aproxima da "perfeição", mas entender quais pontos ainda podem ser melhorados.

\section{Procedimentos metodológicos}

\section{Seleção das obras para o corpus de análise}

Os livros foram selecionados após um levantamento dos exemplares disponíveis nos acervos da Biblioteca Pública Governador Menezes Pimentel (BPGMP), situada na cidade de 
Teófilo, F. B. S.; Gallão, M. I.

Fortaleza (CE); do Laboratório Didático de Ensino de Biologia (LADEB) e do Laboratório de Ensino de Biologia (LEBIO), ambos localizados no Departamento de Biologia da Universidade Federal do Ceará (UFC); em tradicionais sebos de Fortaleza (CE) e em coleções particulares. Nas obras (Quadro 1), deu-se preferência à análise de capítulos introdutórios, onde, geralmente, se procede a abordagem histórica, para explicar, por exemplo, o desenvolvimento das técnicas de microscopia e a elaboração da teoria celular.

Quadro 1 - Lista de livros didáticos de Biologia, selecionados para análise, de acordo com seus intervalos

\begin{tabular}{|c|c|c|c|c|}
\hline Intervalo & Obra & Autor / Ano & Título & Capítulo \\
\hline \multirow[t]{4}{*}{ 1965-1974 } & A & Bolsanello (1965) & Biologia: tomo 1 & $\begin{array}{l}\text { Tópico } 1 \text { - Histórico } \\
\text { celular. }\end{array}$ \\
\hline & B & $\begin{array}{l}\text { Bolsanello; Broocke } \\
\text { Filho; Freiras (1969) }\end{array}$ & Biologia geral. & Histórico celular. \\
\hline & $\mathrm{C}$ & Frota-Pessoa (1970) & $\begin{array}{l}\text { Biologia na escola } \\
\text { secundária: primeiro } \\
\text { volume. } 4 \text {. ed. }\end{array}$ & Capítulo 4 - As células. \\
\hline & $\mathrm{D}$ & $\begin{array}{l}\text { Biological Sciences } \\
\text { Curriculum Study } \\
\text { (1972) }\end{array}$ & $\begin{array}{l}\text { Biological sciences } \\
\text { curriculum study: biologia } \\
\text { das moléculas ao homem } \\
\text { parte I. 11. ed. }\end{array}$ & $\begin{array}{l}\text { Capítulo } 11 \text { - A teoria } \\
\text { celular. }\end{array}$ \\
\hline \multirow[t]{4}{*}{ 1975-1984 } & $\mathrm{E}$ & Barros (1975) & $\begin{array}{l}\text { Novo curso de biologia. } \\
\text { 20. ed. }\end{array}$ & $\begin{array}{l}\text { Capítulo } 5 \text { - A célula ou } \\
\text { protoplasto: fotossíntese e } \\
\text { respiração. }\end{array}$ \\
\hline & $\mathrm{F}$ & Dias; João (1977) & Biologia. & Capítulo 2 - Citologia. \\
\hline & G & Jantsch 1978 & $\begin{array}{l}\text { Elementos de biologia } \\
\text { geral: } 2^{\circ} \text { grau. }\end{array}$ & Capítulo 5 - Introdução. \\
\hline & $\mathrm{H}$ & $\begin{array}{l}\text { Linhares; } \\
\text { Gewandsznajder } \\
(1982)\end{array}$ & $\begin{array}{l}\text { Biologia celular: o } \\
\text { fenômeno da vida: a vida } \\
\text { celular: segundo grau. } 2 \text {. ed. }\end{array}$ & $\begin{array}{l}\text { Capítulo } 4 \text { - A evolução } \\
\text { da estrutura celular. }\end{array}$ \\
\hline \multirow[t]{4}{*}{ 1985-1994 } & $\mathrm{I}$ & $\begin{array}{l}\text { Silva Júnior; Sasson } \\
(1990)\end{array}$ & Biologia 1. 7. ed. & $\begin{array}{l}\text { Capítulo } 3 \text { - A vida a nível } \\
\text { celular. }\end{array}$ \\
\hline & $\mathrm{J}$ & $\begin{array}{l}\text { Amabis; Martho } \\
(1990)\end{array}$ & $\begin{array}{l}\text { Fundamentos da biologia } \\
\text { moderna: livro de } \\
\text { atividades e dicionário de } \\
\text { termos biológicos. } 1 . \text { ed. }\end{array}$ & $\begin{array}{l}\text { Capítulo } 5 \text { - História, } \\
\text { métodos e técnicas em } \\
\text { Citologia. }\end{array}$ \\
\hline & K & $\begin{array}{l}\text { Linhares; } \\
\text { Gewandsznajder } \\
\text { (1992) }\end{array}$ & $\begin{array}{l}\text { Biologia hoje volume } 1 . \\
\text { 2. ed. }\end{array}$ & $\begin{array}{l}\text { Capítulo } 4 \text { - Métodos de } \\
\text { estudo e caracteres gerais } \\
\text { da célula. }\end{array}$ \\
\hline & $\mathrm{L}$ & Soares (1994) & Biologia volume 1.3. ed. & Capítulo 1 - A célula. \\
\hline
\end{tabular}


Quadro 1 - continuação

\begin{tabular}{|c|c|c|c|c|}
\hline Intervalo & Obra & Autor / Ano & Título & Capítulo \\
\hline \multirow[t]{4}{*}{ 1995-2004 } & $\mathrm{M}$ & Uzunian (1997) & Biologia 1. & $\begin{array}{l}\text { Capítulo } 6 \text { - A } \\
\text { célula: membrana e } \\
\text { permeabilidade. }\end{array}$ \\
\hline & $\mathrm{N}$ & Carvalho (1998) & Biologia em foco 1. & Capítulo 12 - A célula. \\
\hline & $\mathrm{O}$ & $\begin{array}{l}\text { Favaretto; Mercadante } \\
(2003)\end{array}$ & Biologia volume único. & $\begin{array}{l}\text { Capítulo } 8 \text { - A célula, um } \\
\text { sistema eficiente. }\end{array}$ \\
\hline & $\mathrm{P}$ & $\begin{array}{l}\text { Amabis; Martho } \\
\text { (2004) }\end{array}$ & Biologia: volume 1. 2. ed. & $\begin{array}{l}\text { Capítulo } 4 \text { - A descoberta } \\
\text { da célula. }\end{array}$ \\
\hline \multirow[t]{4}{*}{ 2005-2014 } & Q & Paulino (2005) & Biologia, volume 1. 1. ed. & $\begin{array}{l}\text { Capítulo } 8 \text { - A célula: } \\
\text { teoria celular; padrões } \\
\text { celulares. }\end{array}$ \\
\hline & $\mathrm{R}$ & $\begin{array}{l}\text { Lopes; Mendonça } \\
(2006)\end{array}$ & Bio: volume 1. 1. ed. & $\begin{array}{l}\text { Capítulo } 3 \text { - Citologia: } \\
\text { surgimento e } \\
\text { desenvolvimento }\end{array}$ \\
\hline & $\mathrm{S}$ & $\begin{array}{l}\text { Santos; Aguilar; } \\
\text { Oliveira (2010) }\end{array}$ & $\begin{array}{l}\text { Ser protagonista: biologia: } \\
\text { ensino médio, } 1^{\circ} \text { ano. } 1 . \text { ed. }\end{array}$ & $\begin{array}{l}\text { Capítulo } 4 \text { - Introdução à } \\
\text { citologia. }\end{array}$ \\
\hline & $\mathrm{T}$ & $\begin{array}{l}\text { Amabis; Martho } \\
\text { (2013) }\end{array}$ & $\begin{array}{l}\text { Biologia em contexto 1: do } \\
\text { universo às células vivas. } \\
\text { 1. ed. }\end{array}$ & $\begin{array}{l}\text { Capítulo } 5 \text { - A descoberta } \\
\text { das células. }\end{array}$ \\
\hline
\end{tabular}

*A análise da obra J privilegiou também um livro de atividades suplementar à obra principal.

Fonte: Elaborado pelos autores.

A seleção privilegiou tanto obras constituídas em livro único quanto aquelas que subdividiam os conteúdos em coleções constituídas por três volumes. Nesses casos, predominantemente, foram escolhidos os exemplares voltados para as turmas de primeiro ano do ensino médio, por possuírem o tema a ser analisado em meio aos seus tópicos programáticos. Outra preocupação foi a adoção de títulos que representassem com maior veracidade as transformações concretizadas nas obras didáticas ao longo do tempo. Assim, optou-se por selecionar quatro livros de coleções distintas para cada intervalo de dez anos, tendo como referência a data da edição expressa nos índices catalográficos.

Efetivamente, dentre os exemplares que compõem o corpus de análise, estão manuais didáticos editados desde 1965 até uma edição do ano de 2013, aprovada no Guia de Livros Didáticos PNLD 2015/Biologia (BRASIL, 2014), que inclusive esteve entre os livros utilizados por professores de Biologia nas escolas públicas cearenses.

\section{Estabelecimento de critérios para análise dos livros didáticos}

Para examinar os capítulos com teor histórico, foi utilizado como orientação um quadro de avaliação (Quadro 2) adaptado daquele sugerido por Krasilchik (2011) em seu livro Prática de ensino de biologia, como um instrumento para a citada finalidade. Também se teve inspiração nas metodologias de avaliação utilizadas nas investigações de obras didáticas das teses 
de doutorado de Leite (2004), Pagliarini (2007) e Silva (2014). Ao todo, foram estabelecidas quatro categorias de avaliação: conteúdo teórico, ilustrações, exercícios, atividades e projetos e a existência de recursos adicionais.

Quadro 2 - Categorias observadas na análise dos livros didáticos de Biologia e suas respectivas descrições

\begin{tabular}{|l|l|}
\hline \multicolumn{1}{|c|}{ Categorias } & \multicolumn{1}{c|}{ Descrições } \\
\hline I. Conteúdo teórico & $\begin{array}{l}\text { existência ou não de citações a episódios históricos; } \\
\text { existência de apresentações inadequadas de História e Filosofia da Ciência } \\
\text { ("pseudo-história" da ciência). }\end{array}$ \\
\hline II. Ilustrações & $\begin{array}{l}\text { existência ou não de ilustrações relacionadas com a História e Filosofia da } \\
\text { Ciência; } \\
\text { organização das figuras relacionadas com História e Filosofia da Ciência } \\
\text { ao longo do capítulo/unidade; } \\
\text { análise das legendas nas figuras relacionadas com História e Filosofia da } \\
\text { Ciência; } \\
\text { relevância das figuras relacionadas com História e Filosofia da Ciência em } \\
\text { relação ao texto. }\end{array}$ \\
\hline $\begin{array}{l}\text { III. Exercícios, } \\
\text { atividades e projetos }\end{array}$ & $\begin{array}{l}\text { existência ou não de propostas, exercícios, atividades e projetos } \\
\text { relacionados com História e Filosofia da Ciência; } \\
\text { análise das propostas relacionadas com História e Filosofia da Ciência no } \\
\text { decorrer do capítulo/unidade. }\end{array}$ \\
\hline IV. Recursos adicionais & $\begin{array}{l}\text { existência ou não de recursos adicionais (leituras complementares) em } \\
\text { relação História e Filosofia da Ciência; } \\
\text { os recursos adicionais relacionados com História e Filosofia da Ciência } \\
\text { dialogam com o conteúdo teórico apresentado ao longo do capítulo/ } \\
\text { unidade? }\end{array}$ \\
\hline
\end{tabular}

Fonte: Elaborado pelos autores.

Como mecanismo para a investigação do conteúdo teórico, os livros didáticos foram submetidos à análise de conteúdo, classificada por Bardin (2011, p. 15) como "um conjunto de instrumentos metodológicos cada vez mais sutis em constante aperfeiçoamento, que se aplicam a 'discursos' (conteúdo e continentes) extremamente diversificados". Assim, na exploração do material, foram verificadas citações com abordagens históricas e filosóficas que faziam referências a episódios relacionados ao desenvolvimento da Biologia Celular. Posteriormente, todas as menções foram recortadas ao "nível semântico", formando unidades de contexto, facilitando a apreciação.

As inadequações foram baseadas nos trabalhos de Gil-Pérez et al. (2001, p. 127), que propuseram uma "reflexão sobre as possíveis deformações que o ensino das ciências poderia (e pode) estar a transmitir, explícita ou implicitamente", e no artigo de Allchin (2004), intitulado Pseudohistory and pseudoscience. Assim, procuramos observar a existência de cinco concepções errôneas das Ciências: 
tífico;

a) a mostra de uma visão superficial, linear e acumulativa do desenvolvimento cien-

b) a expressão de uma ciência regida por um "método científico" único e infalível;

c) a indicação de uma ciência construída por meio de esforços individuais;

d) o apontamento de uma óptica demasiadamente simples da prática científica;

e) revelar um modo de ver anacrônico da ciência.

\section{Resultados e discussão}

Os resultados da análise quantitativa de citações no conteúdo teórico, imagens, propostas, exercícios, atividades, projetos e outros tipos de recursos adicionais que fazem referência a elementos de História e Filosofia da Ciência em capítulos introdutórios ao estudo da Biologia Celular foram agrupados no Quadro 3. Essa organização teve como referência os intervalos estabelecidos anteriormente (Quadro 1), visando a facilitar a comparação entre livros e períodos distintos.

Quadro 3 - Resultados da análise quantitativa nos livros didáticos de Biologia

\begin{tabular}{|c|c|c|c|c|c|}
\hline Intervalo & Obra & $\begin{array}{c}\text { Conteúdo } \\
\text { Teórico }\end{array}$ & Ilustrações & $\begin{array}{c}\text { Exercícios, atividades } \\
\text { e projetos }\end{array}$ & $\begin{array}{l}\text { Recursos } \\
\text { adicionais }\end{array}$ \\
\hline \multirow{4}{*}{$1965-1974$} & A & 19 & 13 & 0 & 0 \\
\hline & $\mathrm{B}$ & 19 & 7 & 0 & 0 \\
\hline & $\mathrm{C}$ & 5 & 2 & 0 & 4 \\
\hline & $\mathrm{D}$ & 37 & 7 & 23 & 1 \\
\hline \multirow{4}{*}{ 1975-1984 } & $\mathrm{E}$ & 3 & 0 & 0 & 0 \\
\hline & $\mathrm{F}$ & 9 & 1 & 0 & 0 \\
\hline & G & 8 & 0 & 9 & 0 \\
\hline & $\mathrm{H}$ & 3 & 1 & 1 & 0 \\
\hline \multirow{4}{*}{ 1985-1994 } & $\mathrm{I}$ & 9 & 2 & 1 & 0 \\
\hline & $\mathrm{J}$ & 14 & 2 & 6 & 0 \\
\hline & $\mathrm{K}$ & 7 & 1 & 5 & 0 \\
\hline & $\mathrm{L}$ & 6 & 1 & 0 & 0 \\
\hline \multirow{4}{*}{ 1995-2004 } & $\mathrm{M}$ & 6 & 1 & 0 & 0 \\
\hline & $\mathrm{N}$ & 6 & 1 & 3 & 0 \\
\hline & $\mathrm{O}$ & 4 & 0 & 0 & 0 \\
\hline & $\mathrm{P}$ & 14 & 6 & 8 & 1 \\
\hline \multirow{4}{*}{ 2005-2014 } & Q & 6 & 3 & 2 & 0 \\
\hline & $\mathrm{R}$ & 7 & 3 & 5 & 0 \\
\hline & $S$ & 15 & 3 & 3 & 0 \\
\hline & $\mathrm{T}$ & 16 & 5 & 2 & 1 \\
\hline
\end{tabular}

Fonte: Elaborado pelos autores. 


\section{Análise dos livros didáticos quanto ao conteúdo teórico}

\section{Quanto à existência de citações a episódios históricos}

No que se refere ao conteúdo teórico, é perceptível o fato de que todos os capítulos introdutórios ao estudo da célula nos livros didáticos apreciados contêm referências a elementos da História da Ciência em meio aos seus textos principais (Quadro 3). Inicialmente, considerável quantidade de menções ao conteúdo histórico pôde ser observada em três das quatro obras (A, B e D), que constituem o intervalo 1965-1974. Com origem, entretanto, no período subsequente, é notória a visível diminuição no número de unidades de contexto. Isso decorre, em parte, de uma redução do espaço dedicado a esse tipo de informação por parte dos autores, em prol da valorização de descrições descontextualizadas das estruturas celulares e suas respectivas funções. Percebe-se, também, que, nas obras adotantes dessa posição, assuntos como o surgimento do microscópio e a elaboração da teoria celular - que, por natureza, necessitam de informações históricas - aparecem discretamente, em geral suprimidos em tópicos isolados no início ou fim dos capítulos, dificultando o diálogo com o resto dos temas abordados. Além dos pontos supracitados, destaca-se a relevância da obra D para o ensino de Biologia do período. Trata-se do único livro traduzido analisado nessa pesquisa, e, lembrado como "um dos materiais curriculares produzidos nos anos 60 que já apresentava preocupação com a contextualização histórica” (CARNEIRO; GASTAL, 2005, p. 34).

Demais citações de caráter histórico só voltam a acontecer quando, ocasionalmente, os autores optam por estabelecer relações com o nome de algum cientista a determinado fundamento da Biologia Celular. No fragmento a seguir, extraído do livro F, nota-se a superficialidade nesse tipo de inserção:

Complexo de Golgi - É constituído por um conjunto de cavidades achatadas, formando bolsas delimitadas por membranas.

O complexo de Golgi foi observado pela primeira vez em 1898 pelo italiano Camillo Golgi (Obra F, 1977, p. 23, grifo nosso).

Segundo autores como Vidal e Porto (2012, p. 299), menções desse caráter não propiciam aos estudantes momentos para o debatimento das práticas científicas e, no geral, "serve[m] apenas para apresentar, exemplificar ou reforçar conteúdos".

Salvo algumas exceções, como na obra J e P, o baixo número de citações se mantém até o intervalo 1995-2004. Nesse ínterim, as abordagens referentes à História e Filosofia da Ciência se restringem a tópicos intitulados como: "Um pouco da história da Citologia" (obra $\mathrm{M})$; e "Um pouco de História" (obra O). A escolha de títulos como esses indica ausência de maior aprofundamento e suscita questionamentos acerca do tema por parte dos autores. Ressalta-se, entretanto, que a obra J, mesmo ao indicar considerável número de menções, ainda optou pela escolha do título "Breve história da descoberta da célula" (obra J).

Desde a metade do último intervalo (2005-2014), observa-se um singelo aumento no total de unidades de contexto (obras S e T), em comparação com os outros livros do mesmo período, e aos intervalos anteriores. Uma das prováveis explicações para esse crescimento é a tentativa de se adequar aos critérios exigidos nas avaliações de obras didáticas 
de Biologia destinadas ao ensino médio, que se iniciaram no ano de 2007. Desde então, o Programa Nacional do Livro Didático (PNLD), se encarregou dos procedimentos avaliativos e da divulgação dos respectivos resultados nos chamados Guia de Livros Didáticos, disponíveis para consulta no sítio do Ministério da Educação.

\section{Quanto às apresentações inadequadas da natureza da ciência ("pseudo-história" da ciência)}

Mesmo com a constante oscilação na quantidade de espaço destinada aos conteúdos históricos, o registro de concepções distorcidas acerca da natureza da ciência, provocada por um mau uso das abordagens históricas ou filosóficas, é um aspecto comum aos intervalos.

Nas obras A e B, por exemplo, o histórico da Biologia Celular é apontado por meio de uma sequência de descobertas ordenadas cronologicamente. Na explicação, os autores estabelecem uma simples associação entre datas, pesquisadores, seus principais feitos e, em alguns casos, curiosidades ou informações complementares, como suas nacionalidades e atuações profissionais. Ao todo, 16 nomes de personagens ligados direta ou indiretamente à História da Citologia são lembrados, como, por exemplo, Robert Hooke, Matthias Schleiden, Theodor Schwann, Ernst Haeckell, Robert Brown e Antonie van Leeuwenhoek, entre outros. O assunto, explanado nesse formato, auxilia a perpetuar uma visão superficial e completamente linear dos eventos que auxiliaram a desenvolver a Biologia Celular. Gil-Pérez et al. (2001, p. 133) consideram que a noção de Ciência linear é, além de demasiadamente simples, prejudicial ao ensino-aprendizagem dos conhecimentos científicos, porquanto omite "frequentes confrontações entre teorias rivais, às controvérsias científicas, [...] [e os] complexos processos de mudança". Além disso, desconsidera a "[...] influência das ideologias na aceitação das teorias "como na relação entre a teoria de Schleiden \& Schwann e ideia da geração espontânea" (MAYR, 2008, p. 124). No decorrer dos procedimentos de análise, outros fragmentos que evidenciam interpretações lineares da prática científica foram encontrados em capítulos das obras:

O microscópio foi descoberto em 1590 por Zacharias Jansen; Robert Hook (século XVII) vê a célula morta pela primeira vez examinando ao microscópio (que procurava aperfeiçoar) uma lâmina de cortiça; Nehemia Grew (século XVII) estuda a célula viva, que denominou vesícula. Malpighi (século XVII) descobre os glóbulos vermelhos, os vasos vegetais e animais, etc.; Leeuwenhoek (século XVII) estuda os infusórios ou cilióforos, as bactérias, o espermatozoide, etc. Foi, porém, no século XIX que Thuret na alga Fucus e Hertwig na estrela-do-mar observaram pela primeira vez a fecundação, sabendo-se, só então, que a vida começa pela célula-ovo. (Obra E, 1975, p. 32).

Nesta época, os conhecimentos sobre a célula já aumentavam com rapidez: complexo de Golgi, centro celular (Boveri), condrioma (Altmann)... microscópio eletrônico... Estes conhecimentos foram sendo acumulados, ordenados, provados e, assim, se constituiu uma ciência dentro da Biologia Geral: a Citologia, ciência que estuda a célula. (Obra G, 1978, p. 39). 
Especificamente sobre o trecho retromencionado, nota-se a tentativa do autor em dimensionar as contribuições realizadas por Camillo Golgi, Theodor Boveri, Richard Altmann, entre outros, como partes constituintes de uma área de estudo ainda maior, no caso, a própria Citologia. Ao citar somente os resultados favoráveis obtidos nos decorreres dos anos, contudo, resta a impressão de que todos esses conhecimentos passaram por um mesmo processo, culminando com suas comprovaçoes definitivas. Além disso, no mesmo fragmento, torna-se a observar a visão simplificada de elaboração da Ciência, ao se divulgar, erroneamente, "a noção de que o conhecimento científico se desenvolve apenas por acumulação" (LEITE, 2004, p. 120, grifo nosso). Em passagem subsequente ao excerto citado, o mesmo autor tenta complementar a ideia de como se deu o desenvolvimento dos estudos da célula. Na ocasião, ele enfatiza o fato de que, para se chegar ao atual estado de entendimento da complexidade celular, deve-se considerar a participação de muitas personagens: "Para chegarmos aos vastos e profundos conhecimentos de citologia hodiernos, muitos biólogos deixaram sua contribuição" (Obra G, 1975, p. 39).

Embora se deve considerar o lado positivo dessa afirmação, principalmente pelo fato de ressaltar que o desenvolvimento da Citologia resulta de um empreendimento coletivo, se faz necessário lembrar que o estudo da célula e de seus componentes não envolveu exclusivamente o trabalho de biólogos, mas também contou com as contribuições de outras personagens de variadas formações, como, por exemplo, estudiosos de outras ciências, com destaque para a Física e a Química.

Outra concepção errônea frequentemente encontrada nos livros didáticos é a visão de que o conhecimento científico pode ser "'provado' definitivamente por alguém no passado" (LEITE, 2004, p. 95, grifo nosso). Pode-se exemplificar essa afirmação com uma passagem expressa nas obras A, no qual os autores tecem comentários sobre Robert Hooke e suas famosas observações de pequenos pedaços de cortiça:

1 - Robert HOOKE - Enquanto os Bandeirantes desvendavam e ampliavam o Brasil, lá na Sociedade Real de Londres, um cientista inglês chamado Robert Hooke, em 1665 apresentava provas de uma descoberta sensacional para a época. Hooke observou que a cortiça era feita de uma sequência de compartimentos que chamou de 'CÉLULAS'. Usou para tanto uma simples lente de aumento. (Obra A, 1965, p. 7, grifo do autor).

No trecho, o autor acaba por propiciar a interpretação de que a observação da cortiça, feita pelo cientista britânico Robert Hooke, fora suficiente para constituir provas concretas ao ponto de determinar um novo conhecimento dentro da Citologia. Além disso, ao fazer uso da expressão descoberta sensacional, comete-se também, um equívoco histórico, porquanto autores como Prestes (1997, p. 24) apontam que "para Hooke, a observação da cortiça foi tão importante quanto qualquer outra que ele fez sobre o microscópio”. Ernst Mayr (MAYR, 2008, p. 121) disserta que, à época, "o estudo dos objetos microscópicos era mais entretenimento do que ciência séria”, citando os primeiros trabalhos que faziam um uso instrumental do microscópio. 
Abrindo um parêntese, uma característica interessante encontrada ainda no excerto anterior é a simples justaposição de informações do evento em questão com um acontecimento decorrido paralelamente no Brasil - no caso, as expedições bandeirantes que aconteceram durante o Período Colonial - numa tentativa de contextualização, mesmo sem qualquer correlação entre ambas. Em outras oportunidades, também nas obras A e B, os autores demonstram uma preocupação em adaptar alguns dos nomes dos cientistas mencionados ao longo do livro, tornando-os, por sua vez, mais familiares aos estudantes brasileiros. Como exemplo, Matthias Jakob Schleiden virou Matias Jacó Schleiden e Ernst Heinrich Haeckel tornou-se Ernesto Henrique Haeckel.

Retomando o ponto sobre os trabalhos de Hooke, notam-se, em diferentes livros didáticos, divergências interpretativas relacionadas aos resultados das observações da cortiça. A mais comum é a errônea atribuição do título de descobridor das células a Robert Hooke. Um exemplo dessa afirmação está na seguinte passagem da obra C: "Quem descobriu as células foi Robert Hooke ao observar, em 1665, um pedaço de cortiça. Êle foi um dos primeiros e mais engenhosos microscopistas". (Obra C, 1970, p. 103, grifo nosso).

Conforme Prestes (1997, p. 25), “a compreensão que temos hoje da célula não deve nada a Hooke, mas aos trabalhos de investigação posteriores a ele - e não derivados dele". A autora também lembra que, à época, não existia nenhuma fundamentação teórica produzida por outros estudiosos, e que, até mesmo o próprio Hooke, não tinha interesses biológicos ao investigar a cortiça. De fato, o pesquisador almejava compreender quais eram as curiosas propriedades que conferiam características específicas ao material, como, por exemplo, "a leveza, a flutuabilidade e a elasticidade" (PRESTES, 1997, p. 22). Outro ponto levantado pela autora supracitada é o fato de que não se pode concluir que esses microscopistas observavam verdadeiramente células, como conhecemos hoje, porquanto muitos termos foram indiscriminadamente utilizados, numa tentativa de designar aquelas novas estruturas. Mayr (2008, p. 122), por exemplo, lembra que "embora se fizesse referência ocasional às células, as referências pareciam enfatizar mais as fibras e outras estruturas longitudinais do que as células".

Além do mencionado, a proposição apresenta Hooke como o grande responsável pela descoberta das células, reforçando a visão de uma Ciência constituída por meio de esforços individuais. Essa noção é, inclusive, amplamente disseminada em outros trechos dos livros analisados. Podemos exemplificar essas situações com um extrato da obra B (também existente na obra A) no qual se confere a Henri Dutrochet o enunciado de uma importante generalização no estudo da Biologia Celular Vegetal: “2 - FRANCISCO DUTROCHET - Em 1824, o francês Dutrochet afirmou: 'Nos tecidos orgânicos dos vegetais tudo é célula'. Poucos deram atenção à afirmação do sábio.” (Obra B, 1969, p. 171, grifo nosso).

Malgrado haverem mostrado que a afirmação não recebeu total atenção da comunidade científica, os autores escolheram atribuir o substantivo sábio a Dutrochet. Embora o pesquisador tenha seus méritos, colocações como essa auxiliam a perpetuar entre os estudantes uma visão deformada da Ciência e, consequentemente, da imagem do cientista. De acordo com Gil-Pérez et al. (2001), tal ideação faz com que os estudantes interpretem os resultados obtidos pelas pesquisas científicas como fruto de trabalhos individuais realizados por gênios isolados, com capacidades intelectuais inigualáveis. Ainda consoante os autores, em muitos casos, também se disseminam "expectativas negativas à maioria, dos alunos com claras discriminações de natureza social e sexual (a ciência é apresentada como uma atividade eminentemente 'masculina')" (GIL-PÉREZ et al., 2001, p. 133). 
Outra concepção errônea identificada foi a mostra de uma visão demasiadamente simples das práticas científicas. No trecho a seguir, por exemplo, o autor comenta, sem maiores justificativas, a adoção da terminologia protoplasma por simplesmente Johann Evangelist Purkinje não gostar da denominação sarcódio que, até então, era utilizada por seus pares: “3 JOÃO EVANGELISTA PURKINJE - († 1869) - De nacionalidade tcheca. Não gostou da designação ‘sarcódio' e mudou para 'protoplasma'.” (Obra B, 1969, p. 171, grifo nosso).

Por último, também se pode observar outro tipo de abordagem inadequada de História e Filosofia da Ciência, principalmente em fragmentos dos três últimos intervalos. Nesses trechos, predomina uma visão anacrônica da Ciência, também conhecida por pesquisadores como whiggismo. Esse termo deriva do livro The whig interpretation of history (1931), de Herbert Butterfield, onde se questionam os problemas derivados de uma interpretação conhecida “[...] dentre outras particularidades, por avaliar o passado em termos do presente" (MARTINS, 2010, p. 2). Ao todo, seis unidades de contexto foram detectadas. Em todas, os autores, utilizando como referência os microscópios atuais, classificam os aparelhos utilizados por Antonie van Leeuwenhoek e Robert Hooke como rudimentares.

A história do estudo das células é na realidade a história do microscópio [...]. Os microscópios usados pelos primeiros citologistas eram muito rudimentares. Ainda assim, esses pesquisadores obtiveram resultados historicamente muito importantes. (Obra I, 1990, p. 12, grifo nosso).

A primeira observação da célula foi feita por Robert Hooke em 1665 [...], com um microscópio muito rudimentar. (Obra L, 1994, p. 88, grifo nosso).

\section{Análise dos livros didáticos quanto às ilustrações}

As imagens foram uma constante nos quatro livros constituintes do intervalo 19651974. As obras A e B, por exemplo, trouxeram grande número de figuras agrupadas em duas páginas dedicadas a ilustrar (cronologicamente) os principais resultados obtidos pelos cientistas citados durante o capítulo. Além de alimentar uma noção linear de desenvolvimento científico, as legendas que acompanham as ilustrações não ajudam a esclarecer, tampouco estabelecer correlações com o texto principal, ou seja, não contribuem para uma correta compreensão histórica da Ciência. Em contrapartida, a obra D, que também exibiu considerável quantidade de imagens, conseguiu instituir um diálogo mais efetivo com o conteúdo teórico, principalmente na explanação acerca do desenvolvimento das técnicas de microscopia.

A obra C, entretanto, trouxe apenas duas figuras que fazem referências ao microscópio monocular utilizado por Robert Hooke e a representação das celas de cortiça. A combinação dessas imagens, em especial, constituiu uma tendência que se repetiu em capítulos de outras 13 diferentes obras (F, H, I, J, K, L, M, N, P, Q, R, S, T), em intervalos distintos. É importante lembrar que, em cinco destas obras, somente essas figuras são associadas a todo o conteúdo histórico.

Mais à frente, no intervalo 1995-2004, a obra P se sobressai por denotar uma variedade considerável de imagens, que vão desde: os microscópios utilizados por Antonie van 
Leeuwenhoek e Robert Hooke; uma representação da obra Micrographia, de Hooke; e desenhos de células elaborados por Theodor Schwann e Walther Fleming. Destaca-se, entretanto, o potencial da imagem utilizada na abertura do capítulo. Na gravura em foco, pode-se notar a realização de uma exposição, sediada na capital francesa, onde a população observa as maravilhas do microscópio. Tal imagem poderia servir como ponto de partida para a realização de um debate envolvendo elementos para além das questões científicas, sobretudo aspectos sociais, culturais e econômicos. No entanto, a gravura não é potencialmente explorada, apresentando-se como um elemento majoritariamente decorativo.

\section{Análise dos livros didáticos quanto aos exercícios, atividade ou projetos}

No que refere às atividades, a obra D (intervalo 1965-1974) foi a primeira, dentre os livros analisados, a indicar uma série de questões propostas. É importante ressaltar que essa é única obra do corpus de análise produzida no exterior, e que, à época, não era costume encontrar exercícios visando a verificação de conteúdos dentre as obras nacionais. Em geral, a maioria das perguntas sugeridas aos estudantes indaga quais são as principais contribuições dos principais cientistas mencionados durante o capítulo. Apesar da menor quantidade, também se percebem questões que exigem compreensão histórica mais abrangente ou, até mesmo, uma articulação de conhecimentos com outras áreas da Biologia.

\section{VERIFIQUE O QUE APRENDEU}

2. Quais os dois acontecimentos que deram início à "revolução científica" do século XVII? [...]

QUESTIONÁRIO [...]

11. Com o que você aprendeu de Biologia, até agora, tente explicar como a teoria celular se adapta à teoria da evolução para formar uma estrutura de idéias mais ampla. (Obra D, 1972, p. 190-196).

Durante o intervalo 1975-1984, os exercícios foram registrados em apenas duas das quatro obras analisadas. A obra $\mathrm{H}$, por exemplo, conta com apenas uma atividade que cuida do contexto histórico de maneira indireta. Já a obra G, traz 9 questões para completar, exigindo dos estudantes uma simples relação entre pesquisadores, datas e suas "descobertas". Além de evidenciar um enfoque de conteúdo, típico dos livros didáticos desse período, e incentivar uma memorização de informações, novamente vem Robert Hooke sendo apontado como o descobridor da célula: "5.5. Robert Hooke (1665) é considerado o descobridor da (Obra G, 1975, p. 40).

Desde o terceiro intervalo (1985-1994) percebe-se que, além dos exercícios de caráter discursivo, os livros passam a adotar questões oriundas de exames vestibulares. $\mathrm{Na}$ obra $\mathrm{K}$, por exemplo, as atividades estão divididas em roteiro para revisão, questões de múltipla escolha e questões discursivas. Os alunos continuam, no entanto, encontrando questões que abordam História da Ciência de maneira superficial, repleta de datas e nomes:

4. (UFPA) A descoberta da célula foi feita em 1665 por

Em 1838 e 1839, e através de 
observações de estruturas de muitas plantas e animais, concluíram que os seres vivos são constituídos por células.

a) Hooke, Weismann, Schwann. b) Wirchow, Schleiden, Schwann. c) Schleiden, Hooke, Schwann. d) Hooke, Schleiden, Schwann. e) Wirchow, Weismann, Hooke. (Obra K, 1992, p. 74).

A questão retrocitada, utilizada em um exame vestibular da Universidade Federal do Pará, aparece em mais cinco obras $(\mathrm{N}, \mathrm{P}, \mathrm{Q}, \mathrm{R}, \mathrm{T})$ que compõem os dois últimos intervalos (1995-2004, 2005-2014). Assim, pode-se inferir que, apesar dos livros terem passado por avaliações e, mais recentemente, adequações ao chamado modelo ENEM, as questões não acompanharam o ritmo de transformações no âmbito da História e Filosofia da Biologia Celular. Tampouco algumas das obras demonstram selecionar ou elaborar novas questões que abordem o conteúdo histórico de modo crítico. Para exemplificar essa carência, pode ser conferida uma questão extraída da obra T (intervalo 2005-2014), na qual se mantém um caráter linear, superficial e decorativo da História da Citologia:

21. 'A descoberta do mundo microscópio é atribuída a (1), cujas observações eram feitas em um (2). Quem denominou a célula foi (3), ao observar a cortiça em um (4)'. Escolha a alternativa em que os números completam corretamente a frase.

a) 1 = Leeuwenhoek; 2 = microscópio composto; $3=$ Hooke; 4 = microscópio simples. b) 1 = Hooke; 2 = microscópio simples; 3 = Leeuwenhoek; 4 = microscópio composto. c) 1 = Leeuwenhoek; 2 = microscópio simples; 3 = Hooke; 4 = microscópio composto. d) 1 = Hooke; 2 = microscópio simples; 3 = Leeuwenhoek; 4 = microscópio simples. (Obra T, 2013, p. 183).

\section{Análise dos livros didáticos quanto aos recursos adicionais}

No primeiro intervalo (1965-1974), a existência de recursos adicionais ocorre por meio de textos complementares somente ao final dos capítulos das obras C e D. Na obra C, os estudantes encontram fragmentos extraídos das obras Micrographia de Robert Hooke, Histoire de la Biologie, de C. Singer, Die cellularpathologie, de Rudolph Virchow, e de um artigo publicado por Theodor Schwann. O autor, por sua vez, realiza comentários por meio de interpolações. Já a obra $\mathrm{D}$ traz um texto intitulado $A$ história dos conceitos biológicos, no qual a teoria celular é inserida em meio a outras teorias e conceitos, como, por exemplo, a teoria da evolução e a genética mendeliana. Em diversas passagens, o autor procura desmistificar uma concepção linear da Ciência e enfatiza a importância de estudar a Biologia por meio de abordagens históricas, entretanto, o trecho ainda apresenta a noção de que existe uma única explicação correta (destacado no fragmento a seguir):

Os conceitos são estabelecidos pelo homem; assim, sua história é a própria história do homem e suas idéias. Isso significa que a Ciência é um empreendimento humano e parte da sua herança cultural. [...] Olhar a 
Biologia na sua perspectiva histórica previne àqueles que imaginam que os caminhos da Ciência levam diretamente ao sucesso. Basta analisar a história das hipóteses feitas entre a época de Darwin e a redescoberta da teoria de Mendel para ver em quantas direções errôneas os pesquisadores podiam tatear à procura de uma resposta. (Obra D, 1972, p. 197, grifo nosso).

Depois dessas aparições, os recursos adicionais voltados para os conteúdos históricos só reaparecem no intervalo 1995-2004 e 2005-2014 (Quadro 3). Uma delas, a obra P, traz um texto de divulgação científica, intitulado Uma história de 400 anos: revelando o mundo invisivel do mundo 'muito pequeno', redigido por um físico e publicado originalmente em um jornal de grande circulação. O mesmo escrito também foi utilizado como recurso complementar na obra T.

É importante ressaltar que - apesar da pesquisa abranger apenas capítulos introdutórios que, geralmente, dissertam sobre o desenvolvimento das técnicas de microscopia e a elaboração da teoria celular - algumas obras apresentam textos sobre outras temáticas ou segmentos nos quais nota-se um reforço para um entendimento correto da Ciência. Contudo, por não se aplicarem diretamente a exemplos relacionados à Biologia Celular, não foram contabilizados. Um destes recortes está presente na obra $\mathrm{R}$, que trouxe o texto Pelos caminhos das descobertas científicas, adaptação de um artigo publicado na revista Science:

[...] Nesse artigo é apontada, numa frase marcante, a dificuldade de se fazer essa síntese da evolução da Ciência: "Os caminhos no descobrimento são suaves e lineares quando a história da Ciência, tortuosa e cheia de nuances, é brutalmente resumida para caber num lugar finito". Este é o nosso caso. Apesar de difícil, essa síntese é importante para que possamos ter uma ideia de como a evolução do conhecimento científico aconteceu. A seguir, você pode acompanhar "uma sequência de eventos" em que são apresentadas contradições e reviravoltas científicas, ironias, tragédias e responsabilidades diante do conhecimento científico. (Obra R, 2006, p. 63).

\section{Considerações finais}

Com base nos resultados deste ensaio, pode-se perceber que a História e Filosofia da Ciência comparece a todos os capítulos dos livros didáticos analisados, independentemente do intervalo. Todavia, nem sempre essas abordagens foram aproveitadas de forma adequada, e que, por muitas vezes, não condizem com a prática científica.

Em virtude disso, foi possível detectar diversas concepções acerca da natureza da ciência que tonificam noções de uma ciência instituídas por uma sequência de acertos, exclusivamente acumulativa, indefectível, individualista e anacrônica. Ademais, em determinados casos, além de distorcer a própria História da Citologia, tais aspectos podem obstaculizar e/ou comprometer o processo de ensino-aprendizagem da célula.

Mesmo com tantos embaraços em sua aplicação, uma vez que essas ferramentas estejam, verdadeiramente, em consonância com a interpretação apropriada dos conteúdos 
históricos, essa prática pode e deve ser considerada opção em potencial para contextualizar e aprofundar assuntos de certa complexidade e altos níveis de abstração, como a própria Biologia Celular.

Ademais, ressalta-se a necessidade de atualizar não só os conteúdos teóricos dos livros didáticos, visando a extirpar a propagação de uma psendo-bistória da ciência, mas também: amodernar recursos acessórios como as imagens e legendas adotadas; diversificar as propostas de exercícios, projetos e outros tipos de materiais complementares, fomentando o debate em sala de aula.

\section{Referências}

ALLCHIN, D. Pseudohistory and pseudoscience. Science \& Education, Dordrecht, v.13, n. 3, p. 179-195, 2004. DOI: https://doi.org/10.1023/B:SCED.0000025563.35883.e9.

AMABIS, J. M.; MARTHO, G. R. A descoberta da célula. In: AMABIS, J. M.; MARTHO, G. R. Biologia: volume 1. 2. ed. São Paulo: Moderna, 2004. p. 90-108.

AMABIS, J. M.; MARTHO, G. R. A descoberta das células. In: AMABIS, J. M.; MARTHO, G. R. Biologia em contexto 1: do universo às células vivas. São Paulo: Moderna, 2013. p. $174-185$.

AMABIS, J. M.; MARTHO, G. R. História, métodos e técnicas em Citologia. In: AMABIS, J. M.; MARTHO, G. R. Fundamentos da biologia moderna. São Paulo: Moderna, 1990. p. $52-62$.

AMABIS, J. M.; MARTHO, G. R. História, métodos e técnicas em citologia. In: AMABIS, J. M.; MARTHO, G. R. Fundamentos da biologia moderna: livro de atividades e dicionário de termos biológicos. São Paulo: Moderna, 1990. p. 25-27.

BARDIN, L. Análise de conteúdo. São Paulo: Edições 70, 2011.

BARROS, L. A. A. A célula ou protoplasto: fotossíntese e respiração. In: BARROS, L. A. A. Novo curso de biologia. 20. ed. São Paulo: Nobel, 1975. p. 31-56.

BATISTA, I. L.; LUCCAS, S. Abordagem histórico-filosófica e educação matemática: uma proposta de interação entre domínios de conhecimento. Educação Matemática Pesquisa, São Paulo, v. 6, n. 1, p. 101-133, 2004. Disponível em: http://revistas.pucsp.br/index.php/ emp/article/view/4682/3252. Acesso em: 1 set. 2015.

BATISTETI, C. B.; ARAÚJO, E. S. N. A.; CALUZI, J. J. As estruturas celulares: o estudo histórico do núcleo e sua contribuição para o ensino de biologia. Filosofia e História da Biologia, São Paulo, v. 4, p. 17-42, 2009.

BIOLOGICAL SCIENCES CURRICULUM STUDY. A teoria celular. In: BIOLOGICAL SCIENCES CURRICULUM STUDY (org). Biologia das moléculas ao homem parte I. 11. ed. São Paulo: EDART, 1972. p. 186-197. 
BOLSANELLO, A. Histórico celular. In: BOLSANELLO, A. (org.). Biologia tomo 1. [São Paulo]: FTD, 1965.

BOLSANELLO, A.; BROOCKE FILHO, J. D.; FREIRAS, O. T. Histórico celular. In: BOLSANELLO, A.; BROOCKE FILHO, J. D.; FREIRAS, O. T. Biologia geral. São Paulo: FTD, 1969. p. 169-186.

BRASIL. Fundo Nacional de Desenvolvimento da Educação. Guia de livros didáticos PNLD 2015: ensino médio biologia. Brasília: FNDE, 2014.

BRASIL. Ministério da Educação. Parâmetros curriculares nacionais ensino médio: parte III: ciências da natureza, Matemática e suas tecnologias. Brasília: MEC, 2000.

BRASIL. Ministério da Educação. Conselho Nacional de Educação. Parecer CNE/CES 1.301/2001. Diretrizes curriculares para os cursos de ciências biológicas. Brasília: CNE, 2001. Disponível em: http://portal.mec.gov.br/cne/arquivos/pdf/CES1301.pdf. Acesso em: 2 mar. 2015.

CARNEIRO, M. H. S.; GASTAL, M. L. História e filosofia das ciências no ensino de biologia. Ciência \& Educação, Bauru, v.11, n.1, p. 33-39, 2005. Disponível em: http:/ / www.scielo.br/pdf/ciedu/v11n1/03.pdf. Acesso em: 15 ago. 2019.

CARVALHO, W. A célula. In: CARVALHO, W. Biologia em foco 1. São Paulo: FTD, 1998, p. $112-117$.

CICILLINI, G. A. A história da ciência e o ensino de biologia. Ensino em Re-vista, Uberlândia, v. 1, n. 1, p. 7-17, 1992. Disponível em: http://www.seer.ufu.br/index.php/ emrevista/article/view/7746/4876. Acesso em: 21 nov. 2015.

DIAS, D. P.; JOÃO, L. C. Citologia. In: DIAS, D. P.; JOÃO, L. C. Biologia. São Paulo: Moderna, 1977. p. 9-72.

EL-HANI, C. N. Notas sobre o ensino de ensino de história e filosofia da ciência na educação científica de nível superior. In: SILVA, C. C. (org.). Estudos de história e filosofia das ciências. São Paulo: Livraria da Física, 2006. p. 3-22.

FAVARETTO, J. A.; MERCADANTE, C. A célula, um sistema eficiente. In: FAVARETTO, J. A.; MERCADANTE, C. Biologia volume único. São Paulo: Moderna, 2003. p. 70-78.

FROTA-PESSOA, O. As células. In: FROTA-PESSOA, O. Biologia na escola secundária: primeiro volume. 4. ed. São Paulo: Companhia Editora Nacional, 1970. p. 101-127.

GIL-PÉREZ, D.; MONTORO, I. F.; ALÍS, J. C.; CACHAPUZ, A.; PRAIA, J. Para uma imagem não deformada do trabalho científico. Ciência \& Educação, Bauru, v. 7, n. 2, p. 125-153, 2001. DOI: https://doi.org/10.1590/S1516-73132001000200001

JANTSCH, L. J. Introdução. In: JANTSCH, L. J. Elementos de biologia geral: $2^{\circ}$ grau. São Paulo: FTD, 1978. p. 38-43.

KRASILCHIK, M. Prática de ensino de biologia. São Paulo: Edusp, 2011. 
LEITE, R. C. M. A produção coletiva do conhecimento científico: um exemplo no ensino de genética. 2004. 211 f. Tese (Doutorado em Educação) - Centro de Ciências da Educação, Universidade Federal de Santa Catarina, Florianópolis, 2004. Disponível em: https://repositorio.ufsc.br/handle/123456789/87537. Acesso em: 29 nov. 2015.

LINHARES, S.; GEWANDSZNAJDER, F. A evolução da estrutura celular. In: LINHARES, S.; GEWANDSZNAJDER, F. Biologia celular: o fenômeno da vida: a vida celular: segundo grau. 2. ed. São Paulo: Ática, 1982. p. 47-63.

LINHARES, S.; GEWANDSZNAJDER, F. Métodos de estudo e caracteres gerais da célula. In: LINHARES, S.; GEWANDSZNAJDER, F. Biologia hoje: volume 1. 2. ed. São Paulo: Ática, 1992, p. 62-78.

LOPES, S.; MENDONÇA, V. L. Citologia: surgimento e desenvolvimento. In: LOPES, S.; MENDONÇA, V. L. Bio: volume 1. São Paulo: Saraiva, 2006. p. 56-78.

MARTINS, L. A. P. Do whiggismo ao priggismo. Boletim de História e Filosofia da Biologia, São Paulo, v. 4, n. 4, p. 2-4, 2010. Disponível em: http:/ /www.abfhib.org/Boletim/ Boletim-HFB-04-n4-Dez-2010.htm. Acesso em: 12 jan. 2016.

MAYR, E. Isto é biologia: a ciência do mundo vivo. São Paulo: Companhia das Letras, 2008.

MOURA, B. A. O que é a natureza da ciência e qual sua relação com a história e filosofia da ciência? Revista Brasileira de História da Ciência, Rio de Janeiro, v. 7, n. 1, p. 32-46, 2014.

PAGLIARINI, C. R. Uma análise da história e filosofia da ciência presente em livros didáticos de física para o ensino médio. 2007. 115 f. Dissertação (Mestrado em Ciências) - Instituto de Física de São Carlos, Universidade de São Paulo, São Carlos, 2007. Disponível em: http://www.teses.usp.br/teses/disponiveis/76/76131/tde-20092007-164233/pt-br.php. Acesso em: 15 jul. 2016.

PAULINO, W. R. A célula: teoria celular; padrões celulares. In: PAULINO, W. R. Biologia, volume 1. São Paulo: Ática, 2005. p. 108-123.

PRESTES, M. E. B. Teoria celular: de Hooke a Schwann. São Paulo: Scipione, 1997.

SANTOS, F. S.; AGUILAR, J. B. V.; OLIVEIRA, M. M. A. Introdução à citologia. In: CATANI, A.; CARVALHO, E. G.; SANTIAGO, F. Ser protagonista: biologia ensino médio $1^{\circ}$ ano. São Paulo: Edições SM, 2010. p. 70-83.

SILVA, C. C. Prefácio. In: SILVA, C. C. (org.). Estudos de história e filosofia das ciências. São Paulo: Livraria da Física, 2006. p. 9-10.

SILVA, E. C. C. A teoria celular em livros didáticos de biologia: uma análise a partir da abordagem histórico-filosófica da ciência. 2014. 290 f. Dissertação (Mestrado em Educação em Ciências e em Matemática) - Setor de Ciências Exatas, Universidade Federal do Paraná, Curitiba, 2014. 
SILVA JÚNIOR, C.; SASSON, S. A vida a nível celular. In: SILVA JÚNIOR, C.; SASSON, S. Biologia 1. 7. ed. São Paulo: Atual, 1990. p. 12-20.

SOARES, J. L. A célula. In: SOARES, J. L. Biologia volume 1. 3. ed. São Paulo: Scipione, 1994. p. 88-102.

UZUNIAN, A. A célula: membrana e permeabilidade. In: UZUNIAN, A. Biologia 1. São Paulo: Harbra, 1997. p. 90-118.

VALE, J. M. F. Educação científica e sociedade. In: NARDI, R. (org.). Questões atuais no ensino de ciências. 2. ed. São Paulo: Escrituras, 2009. p. 9-16.

VIDAL, P. H. O.; PORTO, P. A. A história da ciência nos livros didáticos de química do PNLEM 2007. Ciência \& Educação, Bauru, v. 18, n. 2, p. 291-308, 2012. DOI: https://doi. org/10.1590/S1516-73132012000200004. 
